\title{
The effects of Steel Plate Shear Wall on Residual Capacity of Reinforced Concrete Frame under Sequence Earthquakes by Incremental Dynamic Analysis
}

Hamze Rouhi ( $\square$ hamzerohi@yahoo.com)

Semnan University https://orcid.org/0000-0001-8205-4632

Majid Gholhaki

Semnan University

\begin{abstract}
Research Article
Keywords: Reinforced concrete frame, Steel plate shear wall, Seismic sequence, Residual capacity, Incremental dynamic analysis
\end{abstract}

Posted Date: September 8th, 2021

DOI: https://doi.org/10.21203/rs.3.rs-866641/v1

License: (c) (1) This work is licensed under a Creative Commons Attribution 4.0 International License. Read Full License 


\section{Abstract}

The residual capacity of a damaged structure after the main earthquake is equal to the smallest spectral acceleration of the first mode, which causes local or general failure during the aftershock. In this research, the effect of steel plate shear wall on residual capacity of the reinforced concrete frame under seismic sequence has been investigated. Based on this, four systems of 4, 8, 12, and 24 stories, which represent short, intermediate, tall, are modeled in finite element software and subject to three sets of single and real seismic sequence, taking into account the damage, the effects of mainshock earthquakes have been analyzed under aftershock earthquakes nonlinear increment dynamic analysis (IDA). The analysis showed that in the real seismic sequence, the residual capacity of a reinforced concrete frame with steel plate shear wall in short and intermediate structures on average 3.6 times and tall structures up to 4.25 times compared to the residual capacity of the reinforced concrete frame without steel plate shear wall. Also, in the real seismic sequence, the residual capacity of the structure decreased with increasing the height of short to intermediate structures and intermediate to tall structures, so that this capacity reduction decreased by an average of $70 \%$ in reinforced concrete frame with and without steel plate shear wall.

\section{Introduction}

Because aftershocks usually occur shortly after the main earthquake, and some of these aftershocks cause damage to the structure with a destructive force equal to that of the main earthquake, strengthening the damaged structure of the main earthquake in this short time interval is not possible and to reduce the level of hazards, it is necessary to evaluate the performance of the damaged structure in general under the main earthquake and aftershocks [1].

In 2011, about 100 aftershocks of magnitude six or more occurred four days after the Tohoku earthquake in Japan, causing structural damage and infrastructure damage [2].

In recent years, due to the increasing development of design methods and the tendency of codes to design based on performance, seismic assessment and performance of structures during earthquakes has become one of the most important issues in earthquake engineering. In the performance-based seismic design method, the structure is designed for different levels of expected performance, related to different levels of earthquake risk. An important step in performance-based design is to evaluate the nonlinear seismic response of structures. Accordingly, it is necessary to study the performance of structures during an earthquake and determine the capacity required to resisting possible aftershocks in response to the structure and the possibility of the collapse of the building.

The amount of damage to the structure is directly related to the demand for ductility [3]. Therefore, evaluating the relationship between these two parameters is very important. Current codes only evaluate the ductility demands of a structure in the main earthquake. Research in recent years has shown that the occurrence of aftershocks can significantly increase the demand for ductility of structures and lead to an increase in earthquake risk [4].

The main study of sequence earthquakes since the end of the 19th century has been done by Omori [5]. Omori concluded that the amount of deterioration during an aftershock was inversely related to the deterioration during the main earthquake. One of the first studies by Mahin was conducted in 1980 [6]. Mahin realized that severe aftershocks could double the ductility and displacement demands of many elastoplastic onedegree-of-freedom systems. In addition to Mahin's work, there are several other studies to investigate the seismic performance of one-degree-of-free inelastic systems under a variety of ground motions in an earthquake sequence or various ground motions. These include the research of Elnath et al. In 1998 [7], Sanasaka and Kirmidjian in 2002 [8], Amadio et al. In 2003 [9], Das et al. In 2007 [10], and lancovivi in 2007 [11].

Nicholas and Cornell in 2004 [12] conducted studies to calculate the residual capacity of structures damaged by the main earthquake using nonlinear static and dynamic analyses of time history. The results of this study showed that in the elastic the capacity calculated by two methods is the same but in the inelastic range, the residual capacity curve (for aftershock tolerance) calculated by the static method compared to the dynamic method has a small estimate of the residual capacity. They had a static method in correcting the answer; the capacity calculated dynamically was the main earthquake using the same aftershocks as the main earthquake. On the other hand, since selecting the main earthquake as the aftershock is the worst possible scenario, modifying the capacity curve of the static method is not very correct.

Hotzigeorgio in 2009 [13] proposed nonlinear displacement values suitable for Sequence earthquakes, in addition to Hotzigeorgio in 2010 [14] Studied the demand for ductility and coefficient of the behavior of the nonlinear free degrees system under sequence earthquakes near and far-field. Hotzigeorgio in 2010 [15] examined the response of one degree of freedom structures under sequence earthquakes near and far-field using artificial earthquakes and concluded that the use of the main earthquake in evaluating the inelastic response of structures is contrary to certainty and designers must pay attention to the effects of sequence earthquakes.

Mustafa and Takewaki in 2011[16] examined simple random models and showed the repetition of sequence earthquakes. In addition, they proposed the effects of sequence earthquakes on freedom multi-degree systems. Hotzigeorgio and Liolios in 2010 [17] investigated the effect of seismic sequence on the ductility demand of reinforced concrete frames. According to this research, the seismic sequence has an important effect on the 
response of the structure and ductility demands in seismic sequence can be calculated with high accuracy using a combination of single earthquake demands such as seismic sequence.

Garcia et al. in 2011 [18] assessed the demand for drift in steel frames under sequence seismic records in the near and near fields. The main purpose of this study was to investigate the relationship between the frequency content of the main seismic and aftershock, the effects of aftershocks on the drift and residual drift of freedom multi-degree systems, and to evaluate the difference in response between real and artificial sequence earthquakes.

Research by Efraimiadou et al. in 1997 [19], Di Sarno in 2013 [20], and Abdelnaby and Elnashai in 2014 [21] focused on multi-story reinforced concrete frames. Almost all of this research has been done on the response of two-dimensional free degree systems.

Zhai et al. in 2012 [3] studied the response of inelastic single degree of freedom systems under a variety of ground motions. They compared the different responses of structural demand parameters in aftershocks, such as maximum acceleration, maximum velocity, maximum displacement, and residual displacement with their corresponding values in the main earthquake, and concluded that in potential aftershocks there is an increase in the response of the structure and aftershocks cannot always increase both components of maximum acceleration and maximum velocity in the structure in the same way. In other words, for a fixed structure, aftershocks may increase the maximum acceleration, while there is no maximum velocity. Aftershock may also increase or decrease the residual displacement of structural due to the effects of the main earthquake. Therefore, aftershocks can change the accumulation of damage to structures by affecting the displacement and sometimes reverse the results. Shin et al in 2014 [22], by analysing the fragility of reinforced concrete frames, concluded the change structural performance under sequence earthquake.

Hatzivassiliou et al. in 2015 [23] investigated the effects of real seismic sequence with vertical earthquake components on regular and irregular three-dimensional concrete buildings. The most important result of this research is that the maximum story displacement of the structure under seismic sequence is more than single earthquakes and the displacement and residual drift increase due to seismic sequence compared to the single earthquake.

Raghunandan et al. In 2017 [24] investigated the change in the lateral strength of the structure in helping its residual capacity and according to his research based on incremental dynamic analysis of seven structural models with different lateral design resistances, under a set of seismic sequences Structures designed for maximum lateral forces were more resistant to failure than structures designed for lower seismic levels. Increasing the lateral strength at the design (e.g. using a lower strength reduction coefficient in the US design) can help ensure adequate residual strength in the structure after an earthquake exposure. The results of this study also helped to evaluate how the residual capacity of reinforced concrete frames with lateral strength is less than the required regulations for different levels of earthquake damage.

Salim Bahrami and Gholhaki in 2018[25] conducted an analytical study to evaluate the effects of higher modes of reinforced concrete frames with thin steel plate shear walls under simple pulse. According to their research, the demands of maximum displacement and force for different structures with the ratio of pulse period to the first mode period of vibration is equal to one and with the increase of stories, the effects of higher modes decrease and the most important effects of higher modes are roof shear force and base shear. In 2019 , they also investigated the effect of higher modes and degrees of freedom on the coefficient of reduction of resistance in reinforced concrete frames with steel plate shear walls and the coefficient of reduction of earthquake resistance of far and near fields, which can be different, for a multi-degree of freedom has corrected.

Alberto CUEVAS in 2018 [26] in his PHD dissertation entitled Seismic residual capacity of reinforced concrete frames, while pointing to the lack of studies on assessing the residual capacity of damaged buildings to withstand future aftershocks, comprehensive information Evidence-based reinforcement to assess the residual damage capacity of reinforced concrete buildings and provide a feasibility study. Analytical relationships of the remaining crack width are also prepared and presented in this research.

Kusunoki et al. in 2018 [27] researched a new method for assessing the residual seismic capacity of existing structures with a few degrees of freedom using an accelerometer.

Maeda et al. in 2019 [28] investigated post-earthquake damage and the remaining seismic capacity of structures. In his research, the remaining seismic capacity of the structure was evaluated. Damage was assessed based on the level of damage, taking into account the remaining cracks, crushing of concrete.

Recently, the residual seismic capacity has been evaluated by these researchers based on the response spectrum method.

Steel plate shear wall is a type of system suitable for earthquake and wind lateral loads consists of a series of separate panels, each panel is enclosed inside two beams and columns and a steel plate is connected to the surrounding elements [29]. Use of steel plate shear wall due to stiffness, strength, and significant energy dissipation of seismic, as an effective lateral system in seismic rehabilitation to increase the lateral strength and stiffness of buildings against earthquake (technical rehabilitation strategies) in steel structures are considered. Recently, according to the analysis and design of steel plate shear walls, which requires environmental elements (beams and columns) with high rigidity, to increase the lateral strength and stiffness of concrete buildings with a moment-resisting frame that inherently has such elements is used. Therefore, recently, the reinforced concrete frame with steel plate shear wall has been proposed as a new system against lateral loads [30]. 
Due to the newness of this system, this system needs more numerical and laboratory studies. This research is also part of the researches to better understand this system.

Numerous studies have been done on a type of structural system, including resisting moment frames, braced systems, and concrete shear walls under sequence earthquakes. However, the reinforced concrete frames with steel plate shear walls have been studied from various aspects recently, and therefore the effect of sequence earthquakes (near and far-field) on this system has not been studied.

In this research, the effect of steel plate shear wall on residual capacity of the reinforced concrete frame under seismic sequence has been investigated. For this purpose, some sequence real including the main earthquake and aftershock records have been used. The effects of steel plate shear wall on residual capacity of the reinforced concrete frame under sequence earthquakes by incremental dynamic analysis method.

Research method

The method used in this research is presented with a flowchart of Fig. 1.

\section{Numerical Modeling Validation}

\subsection{Numerical modeling validation of reinforced concrete frame equipped with steel plate shear wall}

Validation of analytical models is one of the steps of research. In this research, to validate the model, the laboratory study of Choi and Park in 2011 [31] according to Fig. 2a has been used. He conducted a laboratory study to investigate the cyclic behavior of walls consisting of boundary elements of reinforced concrete frames and thin steel sheets. To ensure the accuracy of the modelling, the numerical model of the laboratory sample was modelled and analysed in OpenSees finite element software [32]. For modelling, the Nonlinear Beam-Column element has been used for the beam and column elements with deformation control, which can take into account the P- $\Delta$ effect and large deformations. The strip method has been used to model the steel plate [33]. In this method, a truss element is used to model the tensile strips. To model the wide plasticity of the elements in the program, the cross-sections of the beam and column elements are divided into some fibers. Concrete02 and Reinforcing Steel materials can model the downward part of the performance curves that have been used for modelling concrete and steel materials of reinforcements, respectively. To model the actual behavior of the strips that should not react when pressed, Hysteretic materials are used, which with the three-line behavior in tension and pressure gives the strips the property that does not show resistance when under pressure and allows that the diagonal tensile field of a steel shear wall is well modelled. Also, the discussion of concrete confinement of columns is seen in the model. Numerical results from cyclic loading are compared with laboratory results (Fig. 2b). The values of load-bearing capacity, initial stiffness, and energy absorption determined from the experiment and the corresponding simulated model are presented in Table 1. The comparison between the two diagrams in Fig. 1b shows the acceptable accuracy in the modelling phase of this research.

\subsection{Numerical modeling validation of reinforced concrete frame}

Validation of analytical models is one of the steps of research. In this research, to validate the model, the laboratory study of Choi and Park in 2011 [31] according to Fig. 3a has been used [31]. He conducted a laboratory study to investigate the cyclic behavior of reinforced concrete frames. To ensure the accuracy of the modelling, the numerical model of the laboratory sample was modelled and analysed in OpenSees finite element software [32]. For modelling, the Nonlinear Beam-Column element has been used for the beam and column elements with deformation control, which can take into account the P- $\Delta$ effect and large deformations. To model the wide plasticity of the elements in the program, the cross-sections of the beam and column elements are divided into some fibers. Concrete01 and Steel02 materials have been used for modelling concrete and steel materials of reinforcements, respectively. Also, the discussion of concrete confinement of columns is seen in the model. Numerical results from cyclic loading are compared with laboratory results (Fig. 3b). The values of load-bearing capacity, initial stiffness, and energy absorption determined from the experiment and the corresponding simulated model are presented in Table 2 . The comparison between the two diagrams in Fig. $3 \mathrm{~b}$ shows the acceptable accuracy in the modelling phase of this research.

\section{Modelling Of Case Study Structures}

\subsection{Modelling models in Etabs software and the basics of designing steel plate shear walls}

Regarding the classification of structural systems, some have considered the ratio of the height to the smallest horizontal dimension of the structure as a criterion for classifying buildings, and height to the smallest dimension ratios greater than $1.5 \pi$, between $\pi$ and $1.5 \pi$, between $\pi$ and $0.5 \pi$ and less than $0.5 \pi$ are known as high tall, tall, intermediate and short buildings, respectively [34]. Accordingly, in this research, four models of $4,8,12$, and 24 stories with height to the smallest dimension ratios of $0.54,1.09,1.63$, and 3.26 in the classification of short, short, intermediate, and tall structures with a rectangular plan according to Fig. 4 a, is selected with a reinforced concrete frame with steel plate shear wall and high ductility. The height of the stories of the models is 3.4 meters and the roof is considered as a block joist. The construction site of the structures is considered to be 
a high earthquake risk and soil type III. Concrete used in C22 grade concrete structures has a characteristic strength of $220 \mathrm{~kg} / \mathrm{cm} 2$ and rebars of type A3 with a yield stress of $4000 \mathrm{~kg} / \mathrm{cm} 2$. The steel used for equivalent braces is construction soft steel with a yield stress of $2400 \mathrm{~kg} / \mathrm{cm} 2$. In the analysis and design of the studied structures, the sixth [35] and ninth [36] national building regulations and the Iranian 2800 earthquake standard, fourth edition [37] have been used, according to sixth of the National Building Regulations, the deadweight load of stories and roof is $640 \mathrm{~kg} / \mathrm{m} 2$, the live load of stories and roof is $200 \mathrm{~kg} / \mathrm{m} 2$ and a load of walls of stories is $600 \mathrm{~kg} / \mathrm{m}$. For the design of structures, according to the results of laboratory work performed on a reinforced concrete frame with steel plate shear wall and the criteria set by the American loading code ASCE07-2010 [38] for steel plate shear wall, the behavior factor 7 for the reinforced concrete equipped with steel plate shear wall lateral system. The behavior factor 7.5 for the reinforced concrete frame system [37] was used. In addition, the criteria for designing dual systems under the sixth of the National Regulations have been controlled. To design thin steel plate shear walls, according to Canadian and American steel regulations, an equivalent brace is considered instead of each steel plate, and after calculating the cross-sectional area of each brace, the thickness of the steel plate is calculated from equation 1.

$$
t=\frac{2 A b \sin \theta \cos 2 \theta}{\mathrm{L} \sin ^{2} 2 \alpha}
$$

Where $\theta$ is the angle between the brace and the column, $L$ is the span of the frame, is the equivalent cross-sectional area of the brace, $a$ is the angle of formation of the diagonal tensile field in the steel plate After determining the thickness, each plate is converted into some diagonal strips, the cross-section of each strip $A_{s}$, is obtained from equation 2 :

$$
\mathrm{A}_{\mathrm{s}}=\frac{L \cos \alpha+L \sin \alpha}{n} \cdot \mathrm{t}
$$

Where $\mathrm{n}$ is the number of bars. Numerous studies have been performed on the number of required strips, the results of which indicate the adequacy of 10 diagonal strips for the analysis of a thin shear steel shear wall. Given that the columns may buckle under the influence of the diagonal tensile field, the stiffness of the columns should be controlled by equation 3 .

$$
\mathrm{I}_{\mathrm{c}} \geq \frac{0.00307 t h_{S}^{4}}{L}
$$

Where $\mathrm{I}_{\mathrm{C}}$ is a moment of inertia of the columns, story height. Also, to prevent the bending of the upper beam of the steel plate shear wall due to the effect of the asymmetric tensile field, equation 4 must be controlled:

$$
\mathrm{M}_{\mathrm{fpb}} \geq \frac{\sigma_{t y} t L^{2}}{8} \sin ^{2} \alpha
$$

Where $\mathrm{M}_{\mathrm{fpb}}$ is the plastic anchor of the cross-section of the beam and is the final stress of the diagonal tensile field, which for thin plates is equal to their yield stress. Due to the small difference in the intensity of the diagonal tensile field between two adjacent stories, control of this relationship is required only for the end beam, but if the difference between the diagonal tensile fields between two adjacent stories is large, the relationship should be controlled for the middle beams.

To ensure that the perimeter columns can withstand the stresses due to the environmental loads along with the stresses due to the tensile field effect, it is necessary to check equation 5 for the plastic anchor of the columns:

$$
\mathrm{M}_{\mathrm{fpc}} \geq \frac{\sigma_{t y} t h^{2}}{4} \cos ^{2} \alpha
$$

Equivalent tensile bracing was used to model the steel plate shear wall in the design stages due to the impossibility of modelling the steel plate in the model geometry and its analysis by ETABS software. In the last two stories of the 24 story model(tall building), due to the negative shear in the braces, the use of a steel plate shear wall in these stories was avoided in the structure and only the special reinforced concrete frame system was used to deal with the lateral force. The tall building design has special regulations which were checked. Designed structural sections of $4,8,12$, and 24 story models are presented in Figures 4, 5, and 6.

\subsection{Modelling in OpenSees}

For modeling of the beam and column elements (Nonlinear-Beam-Column) the ability to take into account the effect P- $\Delta$ and large deformation, the beams and columns have been used. For modeling of steel plate shear wall strip method is used. In this method of the tensile strip of the truss, the element is used. For the concrete and steel reinforcement materials respectively of materials Concrete02 and Reinforcing Steel materials can model downward part of the performance curves

Page 5/19 
has been used. For the actual behavior of strips is used the materials Hysteretic which allows to use of diagonal tension steel plate shear (s1p $\$ \mathrm{e} 1 \mathrm{p} \$, \mathrm{~s} 2 \mathrm{p} \$ \mathrm{e} 2 \mathrm{p} \$$ and s3p $\$ \mathrm{e} 3 \mathrm{p} \$$ in the positive region of Figure $6 \mathrm{~d}$ ). When compression is applied to steel plate shear wall, using of very low for example 1.e-20 for s1n, s2n, and s3n of the negative region of Figure $6 \mathrm{~d}$ the truss model is modeling the behavior of steel plate shear wall in compression. The property of bracing of the models was calculated that for example this property of bracing of 4 story model is presented in Table 3. In the eight-story model, the thickness of the plate is calculated to be $2 \mathrm{~mm}$ for stories one to six, $1.6 \mathrm{~mm}$ for the seventh story, and $1.1 \mathrm{~mm}$ for the eighth story. In the twelve-story model, the thickness of the plate is $1.1 \mathrm{~mm}$ for the first to fourth stories, $1.8 \mathrm{~mm}$ for the fifth to eighth stories, $1.6 \mathrm{~mm}$ for the ninth and tenth stories, and $1.4 \mathrm{~mm}$ for the eleventh story. And for the twelfth story is $1.1 \mathrm{~mm}$. In the twenty-four story model, the thickness of the sheet in the first story is $4.4 \mathrm{~mm}$, in the second to eighth stories, $3.2 \mathrm{~mm}$, in the ninth to fifteenth stories, $2.9 \mathrm{~mm}$, in the sixteenth story, $2.6 \mathrm{~mm}$, in the seventeenth to eighteenth stories, $2.1 \mathrm{~mm}$, in the nineteenth to twentieth stories, $1.8 \mathrm{~mm}$, in the twenty-first and twenty-second stories, $1.6 \mathrm{~mm}$, in the simplest and third stories, $1.4 \mathrm{~mm}$ and on the twenty-fourth story, $1.1 \mathrm{~mm}$ was calculated and used in the analysis. Also, concrete confinement of columns is considered in the model. OpenSees uses the distributed plasticity by the fiber element. Regarding geometric nonlinearity, it should be said that the effects of geometric nonlinearity are defined by the transfer matrices that are a feature of OpenSees. In the mentioned program, after defining the geometry of the model, the gravitational analyzes are gravitationally analyzed (non-linear static) and by setting the time in the amplitude of the problem to zero before performing the nonlinear dynamic analysis, the gravitational load values remain constant in subsequent dynamic analyzes. The effect of P- $\Delta$ is considered in the analyzes. Since in the case of peripheral frames with considerable stiffness and random rotation relative to the middle frames, for the analysis of the structure designed in Etabs, peripheral frames and their specifications have been used for twodimensional nonlinear analysis. To take into account the effects of P- $\Delta$, the Leaning Column method has been used. The concept of a Leaning Column is used to consider the effect of P- $\Delta$ due to gravitational loads. In this method, an additional bay is defined. Columns between which there are rotating springs with low stiffness are connected to the mainframe with high-rigidity beams. The purpose of defining rotary springs with negativity is negligible so that the leaning columns do not absorb the momentum. Gravity loads are then applied to these columns. In the nonlinear dynamic analysis, the selection of a time interval of 30 seconds between the main earthquakes and aftershocks with zero acceleration amplitude is considered to stabilize the frame under the effect of the main earthquake excitation. $5 \%$ damping was applied for all models. To evaluate the seismic demands of reinforced concrete frames equipped with steel plate shear walls, the parameters of the residual capacity of models have been selected to assess the seismic behavior of models.

\section{Selected Seismic Records In Nonlinear Dynamic Analysis}

\section{Selected seismic records in nonlinear dynamic analysis}

In this study, in the method of real seismic records, three groups of seismic records including records of real main earthquakes with effective peak acceleration and their aftershock records, other real main seismic records with nearly effective peak acceleration and their aftershock records, records of some real main earthquakes used in the research of researchers and their aftershock record have been used.

\subsection{Real seismic records (seismic records with effective peak acceleration)}

To investigate the effect of seismic sequence on the response of reinforced concrete frame with steel plate shear wall, real and recorded Sequence records have been used. The mentioned records have been selected based on the Garcia in 2012 [39] and Ghodrati and Manouchehri Dana study in 2005 [40] in which the effective peak acceleration (EPA) parameter is included. The definition of the EPA parameter, which is similar to the maximum PGA ground acceleration of the acceleration type, is equal to the divided average spectral acceleration of an earthquake with $5 \%$ damping over some time of 0.1 seconds to 0.5 seconds by the standard magnification factor of 2.5. EPA is like the peak ground acceleration PGA of the acceleration type. According to the Ghodrati study and Manouchehri Dana [40], among the proposed parameters for selecting the critical seismic scenario such as peak ground acceleration (PGA), effective peak acceleration (EPA), peak ground velocity (PGV), peak ground displacement (PGD), duration Earthquake and Arias intensity ${ }^{[1]}$ criterion, due to having the highest correlation with other parameters, has been introduced as the most appropriate criterion for selecting the most critical scenario. In such a way that the mentioned records are more critical in terms of the impact on the behavior of the structure and its response than other sequence seismic records recorded in other stations. The reason for using the records presented in this research is to avoid creating uncertainties in introducing the characteristics of the following earthquakes by using artificial methods and sometimes proposed models based on Gutenberg-Richter, Amory, and Beth's laws. Thus, in all selected scenarios from the PEER database, the magnitude, duration, time interval between sequence seismic records, and other seismic properties are real. The conditions for selecting sequence real earthquakes used in this paper, in addition to the fact that the recording stations of the first and second earthquakes are the same and the time interval between them is less than ten minutes, is the discussion of the effective peak acceleration of these earthquakes. So that in the sequence seismic records shown in table 4, both the first earthquake and the second earthquake have an EPA among the other records recorded for the desired earthquake. This group of sequence earthquakes is called real seismic scenarios with EPA.

\subsection{Real seismic records (seismic records with nearly maximum EPA)}

Due to the limited number of selected records, a sequential seismic scenario called with nearly maximum EPA (Table 4) is considered, in which the first or second earthquake is ranked second or final third in terms of the amount of EPA relative to the maximum .With these considerations, 11 sequence records introduced in tables 3 and 4 records have been selected for nonlinear dynamic analysis. According to the unit design for records 
with different PGA intensities according to the Iranian earthquake standard 2800 [37] regarding the comparison of the values of the acceleration response spectra of the earthquakes used in nonlinear dynamic analysis with the values of the standard design spectrum, each sequence to reach $0.3 \mathrm{~g}$ were scaled. The calculated scale coefficients of earthquakes for each model are presented in the last column of Tables 4 and 5 .

\subsection{Real seismic records (seismic records used by researchers)}

Four records of earthquakes used by researchers $[17,42]$ as their main earthquake and aftershock are presented in table 6.

\subsection{Effective characteristics of earthquakes in the response of structures}

In nonlinear time history analysis, the behavior of the structure is observed during the earthquake time and this analysis shows the more realistic behavior of the structure during the earthquake compared to other analyzes. In this type of analysis, the effect of peak ground acceleration, frequency content, and time of the earthquake (effective duration of the earthquake) is well observed.

\subsubsection{Peak ground acceleration}

In this study, to investigate the effect of peak ground acceleration or PGA, a relatively wide range of the ratio of peak ground acceleration aftershock to a main-shock of strong earthquakes has been considered. These ratios are: $0.04,0.18,0.21,0.28,0.32,0.38,0.43,0.46,0.74,0.97,1.23$ for real seismic records of groups 1 and 2 and ratios of $1.06,1.15,1.30$ and 1.89 for accelerometers of group 3.

\subsubsection{Frequency content}

Peak ground motions have a greater effect on the amplitude of vibrations. If the frequency content of the earthquake and vibrational frequencies of the structure are close, an earthquake will cause the greatest intensification in the structure. The frequency content is reflected in the acceleration response spectrum or the Fourier spectrum of its acceleration amplitude. The predominant period of earthquakes Tg was obtained using SeismoSignal [42] software.

\subsubsection{Duration of strong ground}

Research shows that the peak ground acceleration of earthquake alone is not a good quantity to determine the earthquake destruction. Because the damage caused by an earthquake is related to the amount of energy of the earthquake movements in a building. Accordingly, the duration of an earthquake based on the amount of input energy to the structure is defined as an important parameter in determining the response of the structure.

The duration of the earthquake in most cases has a significant effect on the inelastic deformation of the structure and therefore in determining the amount of input energy to the structure, linear and nonlinear analysis of the structural response and also in the statistical method of determining the structure's response to an earthquake is widely used. There are different methods for determining the duration of an earthquake using the characteristics and effective parameters of seismic acceleration. One of these methods is the Trifunac-Brady method, which has defined the period of strong vibration as the time interval in which a significant contribution is added to the square integral of the accelerations, called the acceleration intensity. They have chosen the time interval between the $5 \%$ and $95 \%$ stocks as the period of strong. In this research, the effective duration of earthquakes was obtained by this method with the SeismoSignal software [42] and was used in the nonlinear dynamic analysis of models.

\section{The Results Of The Analysis Of The Main Single Earthquakes}

After modelling, the models are subjected to the earthquake of the main single earthquakes of group one seismic scenario and the results of the analysis are presented for seismic evaluation of the models.

\section{1. Assessment of the residual capacity of models under real seismic sequence for group I (earthquakes with effective peak acceleration).}

The models under the main single-scale acceleration of this group (main earthquake Figure 7) are nonlinear dynamic analyses and their residual capacity is calculated and presented in Table 7.

As can be seen from Table 7, the residual capacity of tall structures with reinforced concrete frame systems equipped with steel shear walls is significantly higher than the residual capacity with reinforced concrete frame systems without steel shear walls.

In table7, Frame equal reinforced concrete frame without steel plate shear wall, SPSW reinforced concrete frame equipped with steel plate shear wall and Res cap, residual capacity, and numbers before Freme and SPSW indicate the number of stories of the model. The compassion of 4 story model capacity with and without steel plate shear walls under the main-shock, aftershock, and sequence of seismic records Chalfant Valley of group I (Figure 8) shows that reinforced concrete frames equipped with steel plate shear wall increase structural capacity in main-shock 3.8 , in aftershock 2.6 and sequence 4.15 equal capacity of reinforced concrete frames without steel plate shear wall.

The compassion of 8 story model capacity with and without steel plate shear walls under the main-shock, aftershock, and sequence of seismic records Chalfant Valley of group I (Figure 9) shows that reinforced concrete frames equipped with steel plate shear wall increase structural capacity

Page $7 / 19$ 
in mainshock 1.95, in aftershock 2.60 and sequence 4.40 equal capacity of reinforced concrete frames without steel plate shear wall.

The compassion of 12 story model capacity with and without steel plate shear walls under the main-shock, aftershock, and sequence of seismic records Chalfant Valley of group I (Figure 10) shows that reinforced concrete frames equipped with steel plate shear wall increase structural capacity in main-shock 7.30 , in aftershock 2.20 and sequence 10.40 equal capacity of reinforced concrete frames without steel plate shear wall.

The compassion of 24 story model capacity with and without steel plate shear walls under the main-shock, aftershock, and sequence of seismic records Chalfant Valley of group I (Figure 11) shows that reinforced concrete frames equipped with steel plate shear wall increase structural capacity in main-shock 5.60, in aftershock 12.15 and sequence 6.12 equal capacity of reinforced concrete frames without steel plate shear wall.

\section{2. Assessment of the residual capacity of models under real seismic sequence for group II (earthquakes with nearly maximum EPA).}

From the results of incremental dynamic analysis under the group II seismic sequence, the residual capacity of the models is calculated and presented in Table 8.

\section{3. Assessment of residual capacity of models under real seismic sequence for group III used by researchers.}

From the results of incremental dynamic analysis under the group III seismic sequence, the residual capacity of the models is calculated and presented in Table 9.

\section{Comparing The Residual Capacity Of Reinforced Concrete Frame Systems With And Without Steel Plate Shear Walls.}

In this part of the research, the residual capacity of the models under the earthquakes of groups I, II, and III are presented comparatively. Table 10 shows that the average residual capacity of models of reinforced concrete frame systems with steel plate shear walls is much larger than the residual capacity of models reinforced concrete frame systems without steel plate shear walls. According to this table, the real seismic sequence, in short structures, the average residual capacity of models of reinforced concrete frame system with steel shear walls is 5.50 and in reinforced concrete frame system without steel plate shear walls is equal to 1.48 which shows an increase of $270 \%$, or in other words, the capacity of the reinforced concrete frame system with steel plate shear walls is 3.70 times compared to the reinforced concrete frame system without steel plate shear walls.

In intermediate structures, on average, the residual capacity of models with reinforced concrete frame systems with steel plate shear walls is 1.88 , and in reinforced concrete frame systems without steel plate shear walls is 0.54 , which shows an increase of approximate $250 \%$ or in other words, the capacity of the reinforced concrete frame system with steel plate shear walls is equal to 3.50 times compared to the reinforced concrete frame system without steel plate shear walls.

In tall structures, on average, the residual capacity of models of reinforced concrete frame systems with steel shear walls is 0.55 , and in reinforced concrete frame systems without steel shear walls is 0.13 which shows an increase of approximate $325 \%$ or in other words, the capacity of the reinforced concrete frame system with steel plate shear walls is 4.25 times equal to that of the reinforced concrete frame system without steel plate shear walls.

In total, according to the analysis, the residual capacity of the reinforced concrete frame system with steel plate shear walls is on average 3.8 times larger than the reinforced concrete frame system without steel plate shear walls. It seems that in seismic sequence, the performance of reinforced concrete frame system with steel plate shear walls is much better than the performance of reinforced concrete frame system without steel plate shear walls.

Table 10 shows that the residual capacity of the structure decreased with increasing the height of short to intermediate structures and intermediate to tall structures so that this capacity reduction decreased by an average of $70 \%$ in reinforced concrete frame with and without steel plate shear wall.

\section{Strategies To Deal With Serious Damage To Structures Under Sequence Earthquakes.}

The use of steel plate shear walls in the reinforced concrete frame, due to the high residual capacity compared to the reinforced concrete frame can significantly reduce the structural damage of the reinforced concrete frame. Especially in tall structures, the use of steel plate shear walls is doubly important.

\section{Conclusion}

In this research, to compare the residual capacity of a reinforced concrete frame with and without steel plate shear wall, four structural models with the number of stories 4, 8, 12 and 24 stories under real sequence earthquakes, finite element software have been used. According to the analysis, the most important results of this research are: 
1. Real seismic sequence, in short structures, the average residual capacity of models with reinforced concrete frame system with steel plate shear walls is equal to 5.50 and in reinforced concrete frame system without steel plate shear walls is equal to 1.48 which is $270 \%$ It shows an increase or in other words, the capacity of the reinforced concrete frame system with steel plate shear walls is 3.7 times compared to the reinforced concrete frame system without steel plate shear walls.

2. In intermediate structures, on average, the residual capacity of models with reinforced concrete frame systems with steel plate shear walls is equal to 1.88 , and in reinforced concrete frame systems without steel plate shear walls is equal to 0.54 , which shows a $250 \%$ increase. In other words, the capacity of the reinforced concrete frame system with steel plate shear walls is equal to 3.5 times compared to the reinforced concrete frame system without steel plate shear walls.

3. In tall structures, on average, the residual capacity of models with reinforced concrete frame systems with steel plate shear walls is equal to 0.55 and in reinforced concrete frame systems without steel plate shear walls is equal to 0.13 in other words, the capacity of the reinforced concrete frame system with steel plate shear walls is equal to 4.25 times compared to the reinforced concrete frame system without steel plate shear walls.

4. The residual capacity of the structure decreased with increasing the height of short to intermediate structures and intermediate to tall structures so that this capacity reduction decreased by an average of $70 \%$ in reinforced concrete frame with and without steel plate shear wall.

5. It seems that reinforced concrete frame without steel plate shear walls due to having much less residual capacity than a reinforced concrete frame with plate steel shear walls, after the aftershock experience may suffer significant damage.

\section{References}

[1] Y. Dong, D.M. Frangopol, Risk and resilience assessment of bridges under main-shock and aftershocks incorporating uncertainties, Engineering Structures, 83 (2015) 198-208.

[2] H. Gavin and W. David, "The 03/11/2011 Mw9.0 Tohoku, Japan Earthquake." U.S. Geological Survey, National Earthquake Information Center (2011).

[3] C.H. Zhai, E.P. Wen, s. Li\& L.L. Xie. "The influences of seismic sequence on the inelastic SDOF System"; Institute of Engineering Mechanics (2012).

[4] Hatzivassiliou. M, Hatzigeorgiou. G.D, "Seismic sequence effects on three-dimensional reinforced concrete buildings"; Soil Dynamics and Earthquake Engineering, 72 77-88 (2015).

[5] Omori, F, “On the after-shocks of earthquakes”; The Journal of the College of Science 7:2,111-200 (1894).

[6] Mahin, S. A. "Effects of duration and aftershocks on inelastic design earthquakes"; the seventh world conference on earthquake engineering. Vol. v: 677-680, (1980).

[7] Elnashi, A. S., Bommer, J. J. and Martinez-Pereira, A. "Engineering implications of strong-motion records from recent earthquakes"; Proc. Of eleventh European Conference on Earthquake Engineering, Paris, France, CD-ROM, (1998).

[8] Mary Beth D. Hueste, Jong-Wha Bai. "Seismic retrofit of a reinforced concrete flat-slab structure" $\square$ Part I, seismic performance evaluation. Engineering Structures 29 page 1165-1177, (2007).

[9] Amadio. C, Fragiacomo. M, Rajgelj S. "The effects of repeated earthquakes ground motions on the non-linear response of SDOF system"; Earthquake Engineering and Structure Dynamics; 32(2):291-308 (2003).

[10] Das, S., Gupta, V. K., and Srimahavishnu, V "Damage-based design with no repairs for multiple events and its sensitivity to seismicity model"; Earthquake Engineering and Structural Dynamic 36:3, 307-325. (2007).

[11] lancovivi, M. and Georgiana, I. "Evaluation of the inelastic demand of structures subjected to multiple ground motions"; Structural Engineering 42,143-154(2007).

[12] Luco N., Bazzurro, P., and Cornnell, C. A “DYNAMIC VERSUS STATIC COMPUTATION OF THE RESIDUAL CAPACITY OF A MAINSHOCK-DAMAGED BUILDING TO WITHSTAND AN AFTERSHOCK”; 13th Conference on Earthquake Engineering, Vancouver, Canada, Paper No.2405, (2004).

[13] Hatzigeorgiou, G. D, and Beskos, D. E. "Inelastic displacement ratios for SDOF structures subjected to repeated earthquakes"; Engineering Structures 31:11, 2744-2755(2009).

[14] Hatzigeorgiou, G. D. "Behavior factors for nonlinear structures subjected to multiple near-fault earthquakes"; Computers and Structures 88:56,309-321(2010).

[15] Hatzigeorgiou, G. D. "Ductility demand spectra for multiple near and far-fault earthquakes"; Soil Dynamics and Earthquake Engineering 304,170183(2010). 
[16] Moustafa, A., and Takewaki, I. "Response of linear single-degree-of-freedom structures to random acceleration sequences"; Engineering Structures 33:4, 1251-1258(2011).

[17] Hatzigeorgiou, G. D, and Liolios AA. "Nonlinear behavior of RC frame under repeated strong ground motions", Soil Dyn Earthquake Engineering 30:1010-25 (2010).

[18] Garcia R., and Negrete-Manriquez C. "Evaluation of drift demands in existing steel frames under as-recorded far-field and near-fault mainshockaftershock seismic sequences", Engineering Structures, Vol. 33, No.2, 621-634 (2011).

[19] Efraimiadou S, Hatzigeorgiou GD, Beskos DE. "Structural pounding between adjacent buildings subjected to strong ground motions"; Structural Engineering Report 215, Department of Civil and Environmental Engineering University of Alberta, Edmonton, Alberta, Canada, (1997).

[20] Di Sarno L. "Effects of multiple earthquakes on inelastic structural response”; Journal of Structural Engineering; 56:673-81(2013).

[21] Abdelnaby A, Elnashai A. "Performance of degrading reinforced concrete frame systems under Tohoku and Christchurch earthquake sequence"; Earthquake Engineering; 18(7):1009-36 (2014).

[22] J. Shin, J. Kim, K. Lee, Seismic assessment of damaged piloti-type RC building subjected to successive earthquakes, Earthquake Engineering \& Structural Dynamics, 43(11) 1603-1619 (2014).

[23] Hatzivassiliou. M, Hatzigeorgiou. G.D, "Seismic sequence effects on three-dimensional reinforced concrete buildings"; Soil Dynamics and Earthquake Engineering, 72 77-88 (2015).

[24] Raghunandan M., Welsh-Huggins, S.J., and Liel, A.B "BENEFITS OF LATERAL STRENGTH IN TERMS OF RESIDUAL CAPACITY"; 16th World Conference on Earthquake, Santiago Chile, Chile, Paper No.2350, (2017).

[25] S. Reza.Salimbahrami, M. Gholhaki, Analytical study to evaluate the effect of higher modes of reinforced concrete moment-resisting frames with thin steel shear wall under simple pulse, Advanced in Structural Engineering, (2018) 1-15.

[26] Cuevas A., "SEISMIC RESIDUAL CAPACITY OF REINFORCED CONCRETE FRAMES”; P.HD Thesis, University of Canterbury,Christchurch, New Zealand, (2018).

[27] Kusunoki K., Hinata D., Hattori Y., and Tsai, A "A new method for evaluating the real-time residual seismic capacity of existing structures using accelerometers: Structures with multiple degrees of freedom"; Japan Architectural Review published by John Wiley \& Sons Australia, Ltd on behalf of Architectural Institute of Japan, (2018).

[28] Maeda M., Al-washali, H., and Matsukawa2, K “AN OVERVIEW OF POST EARTHQUAKE DAMAGE AND RESIDUAL

CAPACITY EVALUATION FOR REINFORCED CONCRETE BUILDINGS IN JAPAN"; 7th ECCOMAS Thematic Conference on

Computational Methods in Structural Dynamics and Earthquake Engineering, Crete, Greece, PP 930-943, (2019).

[29] Astaneh-Asl, A, "Seismic Behavior and Design of Steel Shear Walls"; Steel Technical Information and Product Services Report, Structural Steel Educational Council, Moraga, CA (2001).

[30] Tarkan, G., Yavuz, S. T., Hasan, K., Z., and Salih, Y., "Strengthening of reinforced concrete structures with external steel shear walls"; Journal of Constructional Steel Research, Vol. 70, No. 1, pp.226-235 (2012).

[31]- Choi, I. and Park, H"Cyclic Loading Test for Reinforced Concrete Frame with Thin Steel Infill Plate” J. Struct. Eng., 137(6), 654-664 (2011).

[32] Mazzoni, S., el al.; “OpenSees command language manual”; Pacific Earthquake Engineering Research (PEER) Center (2006).

[33] Sabouri S "Introduction to steel plate shear walls". Nashr Anghize Publications (2000).

[34]Stafford Smith, Alex Coull, Translate by haji Kazemi," Tall Building”.' In: Tall Building Structures: Analysis and Design (In Persian) (1991).

[35] Iranian National Building Code. Applied Loads on Buildings. Part 6. Tehran, Iran: Ministry of Roads \& Urban Development; (2013).

[36] Iranian National Building Code. Design and Implement of Concrete Buildings. Part 9. Tehran, Iran: Ministry of Roads \& Urban Development; (2013).

[37] Code IS. Iranian Code of Practice for Seismic Resistant Design of Buildings 2800. 4th ed. Tehran, Iran: Ministry of Roads \& Urban Development; (2014). 
[38] American Society of Civil Engineers (ASCE). (2014). “Minimum Design Loads for Buildings and Other Structures”. ASCE07-2010.

[39] Garcia R. "Main-shock-Aftershock ground motion features and their influence in buildings seismic response ", Journal of Earthquake Engineering, Vol. 16, pp-719-737(2012).

[40] Godrati.Amiri. G, Manouchehri.Dana. F, Introduction of the most suitable parameter for selection of critical earthquake, Computers \& Structures, 83(8) (2005) 613-626.

[41] Vamvatsikos, D. and Cornell. C.An “Incremental dynamic analysis," Earthquake Engineering. And Dynamic structures, 31(3), pp 491-512., (2002).

[42] Seismosignal, Ver. 2.1, University of Berkley California, USA, (2001).

\section{Tables}

Table 1. Comparison of Finite Element Analysis Results [32] and Choi and Park Model Test [31].

\begin{tabular}{|c|c|c|c|c|c|c|c|c|}
\hline \multicolumn{3}{|c|}{ Lateral Load (kN) } & \multicolumn{2}{|c|}{$\begin{array}{l}\text { Elastic Stiffness } \\
(\mathrm{kN} / \mathrm{mm})\end{array}$} & \multicolumn{4}{|c|}{$\begin{array}{l}\text { Energy Dissipation } \\
\text { (kN.m) }\end{array}$} \\
\hline \multirow[t]{4}{*}{ Test } & Finite & Ratio & Test & Finite & Ratio & Test & Finite & Ratio \\
\hline & Element & Finite & & Element & Finite & & Element & Finite \\
\hline & & Element & & & Element & & & Element \\
\hline & & To Test & & & To Test & & & To Test \\
\hline 886 & 903 & 1.02 & 53 & 48 & 0.91 & 323.98 & 349.23 & 1.08 \\
\hline
\end{tabular}

Table 2. Comparison of Finite Element Analysis Results [32] and Choi and Park Model Test [31].

\begin{tabular}{cccccc} 
Lateral Load $(\mathrm{kN})$ & & \multicolumn{2}{l}{ Elastic Stiffness $(\mathrm{kN} / \mathrm{mm})$} \\
\hline Test & Finite Element & $\begin{array}{l}\text { Ratio Finite } \\
\text { Element To Test }\end{array}$ & Test & Finite Element & Ratio Finite \\
& & 0.91 & 6 & 6 & 1 \\
\hline 190 & 173 & Element To Test & 1
\end{tabular}

Table 3. Summary of calculations of bracing equivalent for 4 story model.

\begin{tabular}{llll} 
Story & equivalent cross-sectional area of the brace $\left(\mathrm{cm}^{\wedge} 2\right)$ & $\begin{array}{l}\text { Plate } \\
\text { Thickness }(\mathrm{mm})\end{array}$ & $\begin{array}{l}\text { cross-section of As ( } \\
\text { each strip)(10 strips) }\end{array}$ \\
\hline 1 & 52 & 1.6 & 9.51 \\
\hline 2 & 52 & 1.6 & 9.51 \\
\hline 3 & 52 & 1.6 & 9.51 \\
\hline 4 & 36 & 1.1 & 6.5
\end{tabular}


Table 4. The result for scaling the first category records of seismic scenario (with maximum EPA).

\begin{tabular}{|c|c|c|c|c|c|c|c|c|c|c|c|}
\hline \multicolumn{4}{|c|}{$\begin{array}{l}\text { Scale coefficient } \\
\text { of Models }\end{array}$} & \multirow{2}{*}{$\begin{array}{l}\text { EPA } \\
\text { Mainshock, } \\
\text { Aftershock }\end{array}$} & \multirow[t]{2}{*}{$\begin{array}{l}\text { Ratio PGA } \\
\text { Aftershock } \\
\text { to } \\
\text { Mainshock }\end{array}$} & \multirow{2}{*}{$\begin{array}{l}\text { PGA(g) } \\
\text { Aftershock } \\
\text { Earthquake }\end{array}$} & \multirow{2}{*}{$\begin{array}{l}\text { PGA(g) } \\
\text { Mainshock } \\
\text { Earthquake }\end{array}$} & \multirow{2}{*}{$\begin{array}{l}\text { Aias } \\
\text { Intensity } \\
\mathrm{cm} / \mathrm{s}\end{array}$} & \multirow{2}{*}{$\begin{array}{l}\text { Year month } \\
\text { day } \\
\text { Time }\end{array}$} & \multirow[t]{2}{*}{$\begin{array}{l}\text { Station } \\
\text { name }\end{array}$} & \multirow[t]{2}{*}{$\begin{array}{l}\text { Earthquake } \\
\text { name }\end{array}$} \\
\hline $24 s t$ & $12 s t$ & $8 s t$ & $4 s t$ & & & & & & & & \\
\hline \multirow[t]{2}{*}{1.16} & \multirow[t]{2}{*}{0.89} & \multirow[t]{2}{*}{0.78} & \multirow[t]{2}{*}{0.67} & \multirow[t]{2}{*}{$0.4854,0.1047$} & \multirow[t]{2}{*}{0.32} & \multirow[t]{2}{*}{0.143} & \multirow[t]{2}{*}{0.446} & 193.3 & $86-07-21$ & \multirow{2}{*}{$\begin{array}{l}\text { CDMG } \\
54428 \\
\text { Zack } \\
\text { Brothers } \\
\text { Ranch }\end{array}$} & \multirow{2}{*}{$\begin{array}{l}\text { Chalfant } \\
\text { Valley }\end{array}$} \\
\hline & & & & & & & & 11 & $14: 42,14: 51$ & & \\
\hline \multirow[t]{2}{*}{5.36} & \multirow[t]{2}{*}{4.32} & \multirow[t]{2}{*}{4.10} & \multirow[t]{2}{*}{4.70} & \multirow{2}{*}{$\begin{array}{l}0.0725- \\
0.0794\end{array}$} & \multirow[t]{2}{*}{0.97} & \multirow[t]{2}{*}{0.072} & \multirow[t]{2}{*}{0.074} & 13.3 & 61-04-09 & \multirow{2}{*}{$\begin{array}{l}\text { USGS } \\
1028 \\
\text { Hollister } \\
\text { city Hall }\end{array}$} & \multirow[t]{2}{*}{ Hollister } \\
\hline & & & & & & & & 9.6 & $7: 23,7: 25$ & & \\
\hline \multirow[t]{2}{*}{2.19} & \multirow[t]{2}{*}{1.69} & \multirow[t]{2}{*}{1.50} & \multirow[t]{2}{*}{1.23} & \multirow[t]{2}{*}{$0.2601-0.043$} & \multirow[t]{2}{*}{0.21} & \multirow[t]{2}{*}{0.053} & \multirow[t]{2}{*}{0.255} & 65.2 & $87-03-02$ & \multirow{2}{*}{$\begin{array}{l}99999 \\
\text { Matahina } \\
\text { Dam }\end{array}$} & \multirow{2}{*}{$\begin{array}{l}\text { New } \\
\text { Zealand }\end{array}$} \\
\hline & & & & & & & & 2.6 & $1: 42,1: 51$ & & \\
\hline
\end{tabular}

Table 6. Records with after-earthquake acceleration to main earthquake ratio greater than one [17, 42].

\begin{tabular}{lllllll} 
NO & Earthquake & RSN & Magnitude & Intensity Arias(cm/s) & PGA(g) & Mechanism \\
\hline 1 & Chalfant Valley & 547 & 5.77 & 53.7 & 0.236 & Strike-slip \\
\hline \multirow{2}{*}{2} & Chalfant Valley & 558 & 6.19 & 193.8 & 0.447 & Strike-slip \\
\hline \multirow{2}{*}{3} & Coalinga & 406 & 5.77 & 82.8 & 0.519 & Reverse \\
\hline & Coalinga & 418 & 5.21 & 142.4 & 0.677 & Reverse \\
\hline 4 & Imperial Valley & 185 & 6.53 & 86 & 0.221 & Strike-slip \\
\hline & Whittier & 691 & 5.99 & 30.5 & 0.255 & Strike-slip \\
\hline & Whittier & 716 & 5.27 & 17.5 & 0.194 & Reverse-oblique \\
\hline
\end{tabular}

Table 7. Residual capacity of models under real seismic sequence for group I earthquakes with effective peak acceleration.

\begin{tabular}{|c|c|c|c|c|c|c|c|c|c|c|c|c|}
\hline Earthquake & 1 & 2 & Res cap & \%Res cap & 3 & 4 & Res cap & \%Res cap & 5 & 6 & Res cap & \%Res cap \\
\hline 4Frame & 3.3 & 5.25 & 1.72 & $32.8 \%$ & 4.95 & 5.85 & 1.72 & $29.4 \%$ & 1.42 & 1.42 & 0.66 & $46.5 \%$ \\
\hline 4SPSW & 12.55 & 13.15 & 7.13 & $54.2 \%$ & 5.25 & 9.95 & 7.13 & $71.7 \%$ & 3.72 & 5.02 & 3.04 & $60.6 \%$ \\
\hline 8Frame & 7.8 & 6.16 & 2.08 & $33.8 \%$ & 2.08 & 2.08 & 0.87 & $41.8 \%$ & 3.3 & 1.68 & 1.42 & $84.5 \%$ \\
\hline 8SPSW & 15.15 & 15.95 & 9.17 & $57.5 \%$ & 13.25 & 11.28 & 5.45 & $48.3 \%$ & 8.08 & 7.8 & 4.06 & $52.1 \%$ \\
\hline 12Frame & 1.42 & 2.8 & 0.4 & $14.3 \%$ & 1.42 & 1.93 & 0.27 & $14.0 \%$ & 2.08 & 2.08 & 0.32 & $15.4 \%$ \\
\hline 12SPSW & 10.33 & 6.17 & 4.15 & $67.3 \%$ & 9.22 & 11.53 & 0.057 & $0.5 \%$ & 3.57 & 3.57 & 0.25 & $7.0 \%$ \\
\hline 24Frame & 0.35 & 0.23 & 0.08 & $34.8 \%$ & 0.23 & 0.23 & 0.04 & $17.4 \%$ & 0.6 & 0.23 & 0.07 & $30.4 \%$ \\
\hline 24SPSW & 1.85 & 2.8 & 0.49 & $17.5 \%$ & 0.67 & 0.23 & 0.23 & $100.0 \%$ & 1.42 & 1.2 & 0.56 & 46.7 \\
\hline
\end{tabular}

Table 8. Residual capacity of models under real seismic sequence for group II earthquakes with nearly maximum EPA. 


\begin{tabular}{lllllllllllll} 
Earthquake & 1 & 2 & Res cap & Res cap & 3 & 4 & Res cap & Res cap & 5 & 6 & Res cap & Res cap \\
\hline 4Frame & 2.8 & 3.57 & 0.87 & $24.4 \%$ & 2.8 & 5.25 & 1.72 & $32.8 \%$ & 2.08 & 3.3 & 1.56 & $47.3 \%$ \\
\hline 4SPSW & 8.08 & 12.05 & 11.5 & $95.4 \%$ & 18.55 & 17.75 & 13.55 & $76.3 \%$ & 13.6 & 13.7 & 10.33 & $75.4 \%$ \\
\hline 8Frame & 3.57 & 4.1 & 2.24 & $54.6 \%$ & 3.3 & 6.16 & 1.66 & $26.9 \%$ & 3.56 & 3.3 & 1.32 & $40.0 \%$ \\
\hline 8SPSW & 9.17 & 7.76 & 1.32 & $17.0 \%$ & 6.8 & 10.5 & 1.89 & $18.0 \%$ & 7.8 & 7.13 & 2.55 & $35.8 \%$ \\
\hline 12Frame & 0.8 & 1.42 & 0.71 & $50.0 \%$ & 1.93 & 1.93 & 0.53 & $27.5 \%$ & 1.27 & 2.55 & 0.93 & $36.5 \%$ \\
\hline 12SPSW & 5.85 & 7.13 & 0.8 & $11.2 \%$ & 3.57 & 6.17 & 5.45 & $88.3 \%$ & 8.15 & 5.25 & 1.56 & $29.7 \%$ \\
\hline 24Frame & 0.23 & 0.23 & 0.094 & $40.9 \%$ & 0.23 & 0.23 & 0.07 & $30.4 \%$ & 0.23 & 1.2 & 0.34 & $28.3 \%$ \\
\hline 24SPSW & 0.6 & 2.55 & 0.75 & $29.4 \%$ & 2.08 & 2.08 & 0.27 & $13.0 \%$ & 1.42 & 2.8 & 0.8 & $28.6 \%$
\end{tabular}

8 Continous of Table

\begin{tabular}{|c|c|c|c|c|c|c|c|c|c|c|c|c|}
\hline Earthquake & 7 & 8 & Res cap & Res cap & 9 & 10 & Res cap & Res cap & 11 & 12 & Res cap & Res cap \\
\hline 4Frame & 1.42 & 3.3 & 0.67 & $20.3 \%$ & 1.42 & 0.8 & 0.8 & $100.0 \%$ & 1.42 & 1.42 & 0.55 & $38.7 \%$ \\
\hline 4SPSW & 7.8 & 9.95 & 9.95 & $100.0 \%$ & 3.3 & 20 & 16.2 & $81.0 \%$ & 2.08 & 1.2 & 1.2 & $100.0 \%$ \\
\hline 8Frame & 2.55 & 4.95 & 0.74 & $14.9 \%$ & 2.55 & 2.55 & 1.66 & $65.1 \%$ & 2.8 & 3.3 & 3.3 & $100.0 \%$ \\
\hline 8SPSW & 2.76 & 9.22 & 0.23 & $2.5 \%$ & 4.38 & 8.15 & 4.1 & $50.3 \%$ & 6.12 & 4.38 & 3.7 & $84.5 \%$ \\
\hline 12Frame & 1.42 & 1.27 & 0.33 & $26.0 \%$ & 0.67 & 1.2 & 0.71 & $59.2 \%$ & 0.8 & 2.8 & 0.62 & $22.1 \%$ \\
\hline 12SPSW & 3.57 & 4.1 & 0.05 & $1.2 \%$ & 2.8 & 4.1 & 2.9 & $70.7 \%$ & 9.95 & 5.85 & 5.85 & $100.0 \%$ \\
\hline 24Frame & 0.23 & 0.8 & 0.17 & $21.3 \%$ & 0.67 & 0.62 & 0.26 & $41.9 \%$ & 0.6 & 0.23 & 0.15 & $65.2 \%$ \\
\hline 24SPSW & 1.42 & 0.8 & 0.18 & $22.5 \%$ & 2.08 & 1.42 & 1.27 & $89.4 \%$ & 0.8 & 1.27 & 0.8 & $63.0 \%$ \\
\hline
\end{tabular}

8 Continous of Table

\begin{tabular}{lllllllll} 
Earthquake & 13 & 14 & Res cap & Res cap & 16 & 17 & Res cap & Res cap \\
\hline 4Frame & 2.08 & 4.38 & 1.2 & $27.4 \%$ & 3.56 & 5.85 & 0.93 & $15.9 \%$ \\
\hline 4SPSW & 2.15 & 2.08 & 0 & $0.0 \%$ & 1 & 1 & 0 & $0.0 \%$ \\
\hline 8Frame & 4.38 & 4.38 & 1.93 & $44.1 \%$ & 2.55 & 8.15 & 1.85 & $22.7 \%$ \\
\hline 8SPSW & 5.21 & 0.18 & 0 & $0.0 \%$ & 5.8 & 2.76 & 2.34 & $84.8 \%$ \\
\hline 12Frame & 1.42 & 2.08 & 0.36 & $17.3 \%$ & 1.42 & 2.55 & 0.4 & $15.7 \%$ \\
\hline 12SPSW & 4.38 & 6.8 & 0.74 & $10.9 \%$ & 4.38 & 2.08 & 2.08 & $100.0 \%$ \\
\hline 24Frame & 0.23 & 0.6 & 0.05 & $8.3 \%$ & 0.23 & 0.23 & 0.23 & $100.0 \%$ \\
\hline 24SPSW & 1.42 & 0.8 & 0.23 & $28.8 \%$ & 0.62 & 3.57 & 0.23 & $6.4 \%$
\end{tabular}

Table 9. Residual capacity of models under real seismic sequence for group III earthquakes.

\begin{tabular}{lllllllllllll} 
Earthquake & 185 & 208 & Res cap & Res cap & 406 & 418 & Res cap & Res cap & 547 & 558 & Res cap & Res cap \\
\hline 4Frame & 1.2 & 2.08 & 0.55 & $26.4 \%$ & 2.8 & 4.38 & 1.32 & $30.1 \%$ & 2.8 & 3.3 & 1.47 & $44.5 \%$ \\
\hline 4SPSW & 4.1 & 5.25 & 5.25 & $100.0 \%$ & 16.2 & 17.6 & 12.3 & $69.9 \%$ & 5.85 & 12.71 & 12.71 & $100.0 \%$ \\
\hline 8Frame & 2.08 & 5.25 & 0.38 & $7.2 \%$ & 3.57 & 5.25 & 1.66 & $31.6 \%$ & 3.3 & 6.16 & 3.08 & $50.0 \%$ \\
\hline 8SPSW & 1.27 & 11.1 & 5.45 & $49.1 \%$ & 6.17 & 7.13 & 0.3 & $4.2 \%$ & 5.25 & 14.85 & 0.36 & $2.4 \%$ \\
\hline 12Frame & 0.8 & 0.66 & 0.14 & $21.2 \%$ & 1.42 & 2.08 & 0.76 & $36.5 \%$ & 2.08 & 1.27 & 1.2 & $94.5 \%$ \\
\hline 12SPSW & 1.41 & 6.8 & 1.12 & $16.5 \%$ & 4.1 & 5.25 & 0.71 & $13.5 \%$ & 3.3 & 10.33 & 2.55 & $24.7 \%$ \\
\hline 24Frame & 0.6 & 0.23 & 0.036 & $15.7 \%$ & 0.62 & 0.66 & 0.23 & $34.8 \%$ & 0.66 & 0.23 & 0.15 & $65.2 \%$ \\
\hline 24SPSW & 2.55 & 0.67 & 0.23 & $34.3 \%$ & 2.08 & 2.08 & 0.8 & $38.5 \%$ & 1.42 & 1.42 & 0.834 & $58.7 \%$
\end{tabular}


Continous of Table 9

\begin{tabular}{lllll} 
Earthquake & 691 & 716 & Res cap & Res cap \\
\hline 4Frame & 2.55 & 3.57 & 2.55 & $71.4 \%$ \\
\hline 4SPSW & 6.8 & 16.2 & 7.13 & $44.0 \%$ \\
\hline 8Frame & 3.56 & 4.38 & 1.66 & $37.9 \%$ \\
\hline 8SPSW & 10.3 & 7.13 & 1.08 & $15.1 \%$ \\
\hline 12Frame & 0.8 & 2.55 & 0.76 & $29.8 \%$ \\
\hline 12SPSW & 7.8 & 6.16 & 2.55 & $41.4 \%$ \\
\hline 24Frame & 0.23 & 0.8 & 0.23 & $28.8 \%$ \\
\hline 24SPSW & 0.8 & 2.08 & 0.8 & $38.5 \%$
\end{tabular}

Table 10. Comparison of the residual capacity of models under earthquakes of groups I, II, and III.

\begin{tabular}{llll} 
Earthquake & groups I & groups II & groups III \\
\hline 4Frame & 1.37 & 1.04 & 1.47 \\
\hline 4SPSW & 5.77 & 7.84 & 9.35 \\
\hline 8Frame & 1.46 & 1.84 & 1.70 \\
\hline 8SPSW & 6.23 & 2.02 & 1.80 \\
\hline 12Frame & 0.33 & 0.57 & 0.72 \\
\hline 12SPSW & 1.49 & 2.43 & 1.73 \\
\hline 24Frame & 0.06 & 0.17 & 0.16 \\
\hline 24SPSW & 0.43 & 0.57 & 0.67
\end{tabular}

Due to technical limitations, Table 5 is only available as a download in the Supplemental Files section.

\section{Figures}




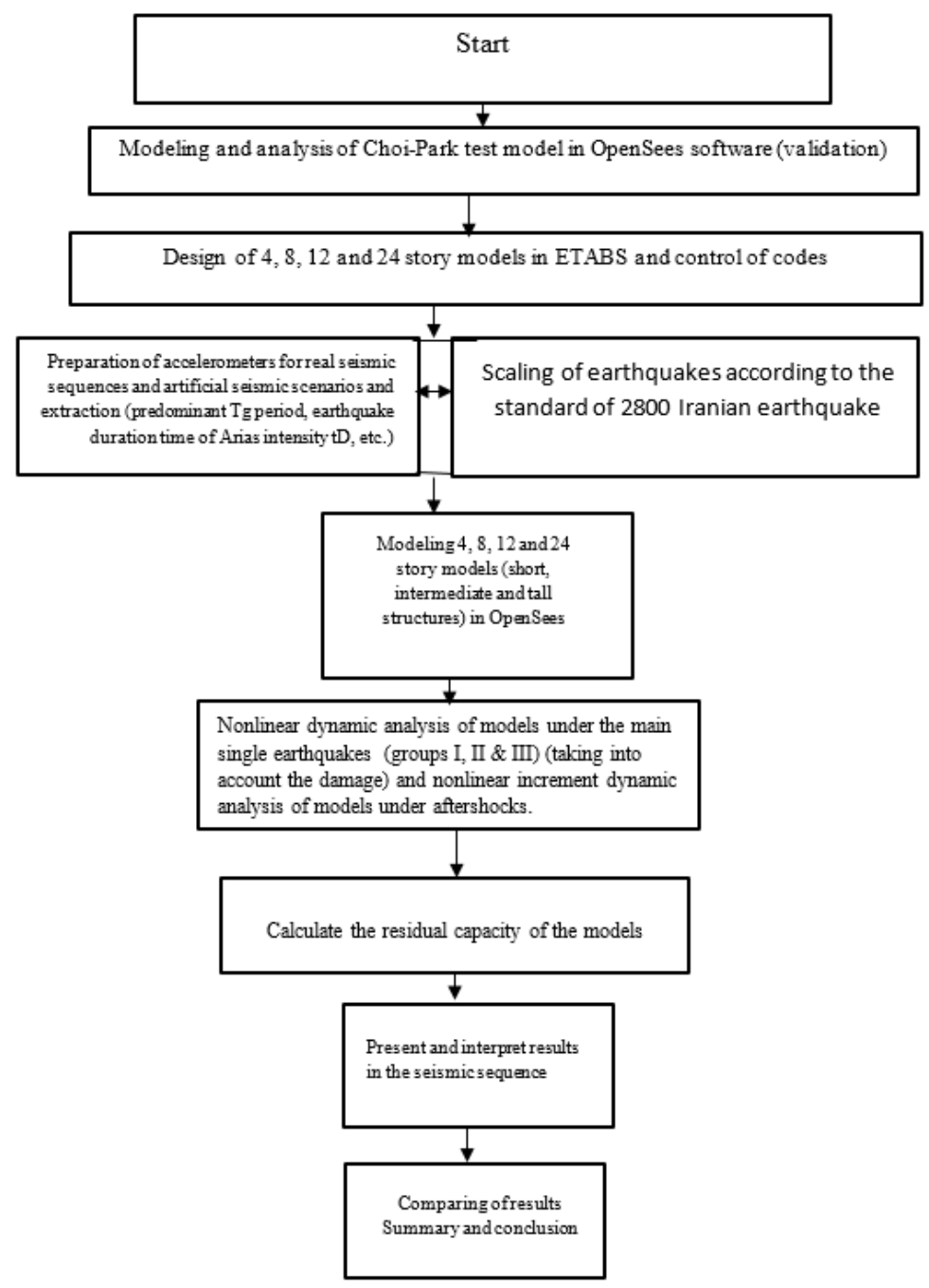

Figure 1

Flowchart of methodology

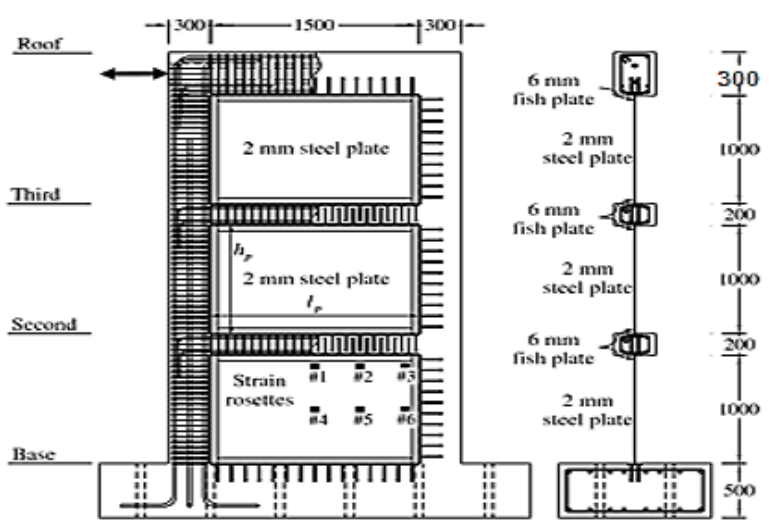

(a)

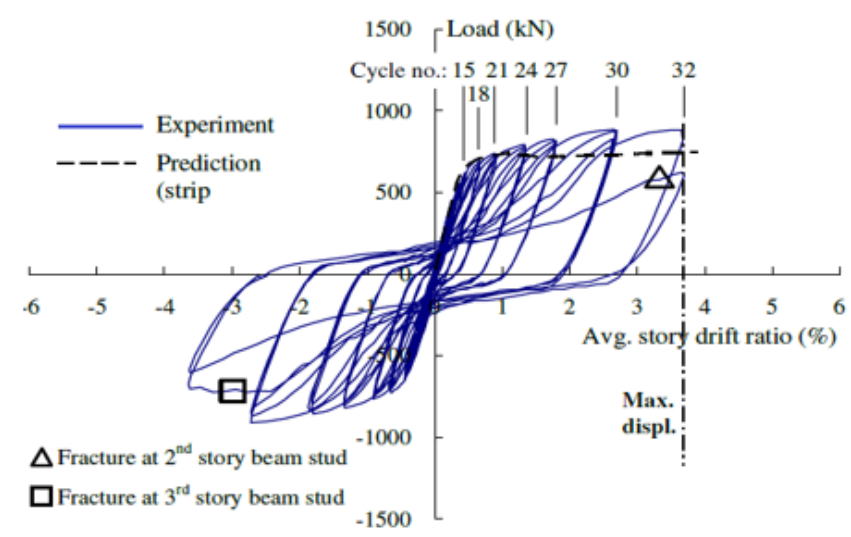

(b)

Figure 2

(a) Geometric and reinforcing details of the concrete frame equipped with thin steel plate infill wall [31] (b) Hysteresis curve of numerical model [32] and Choi and Park laboratory sample [31]. 


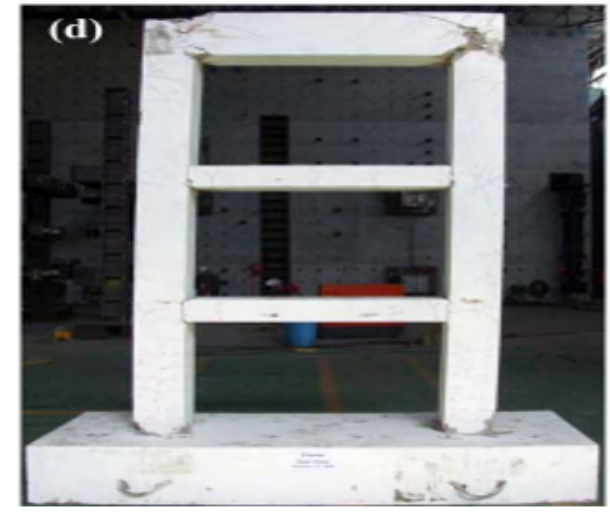

(a)

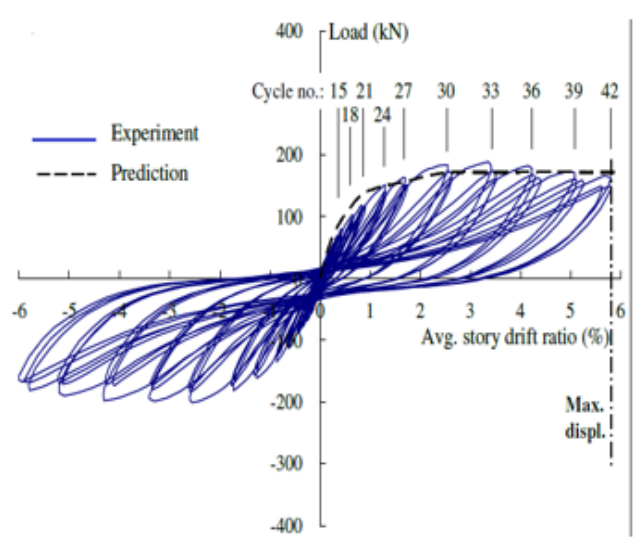

(b)

Figure 3

(a) Reinforced Concrete Frame [31] (b) Hysteresis curve of numerical model [32] and Choi and Park laboratory sample [31].
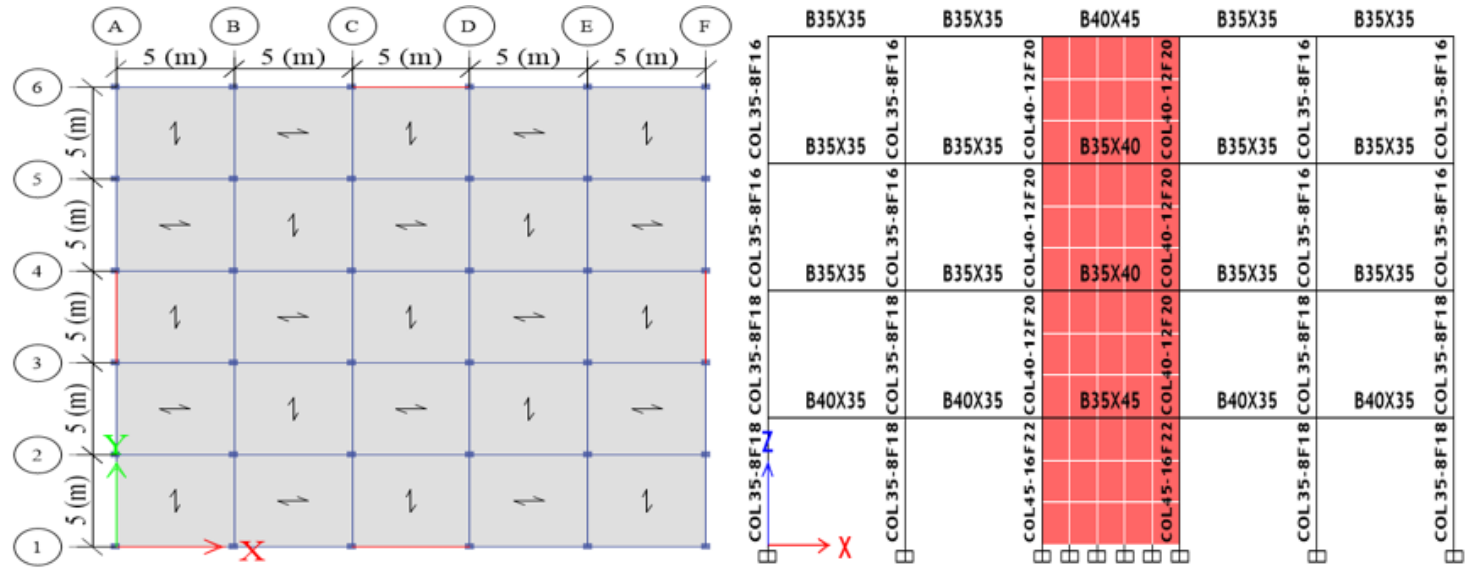

(a)

(c)
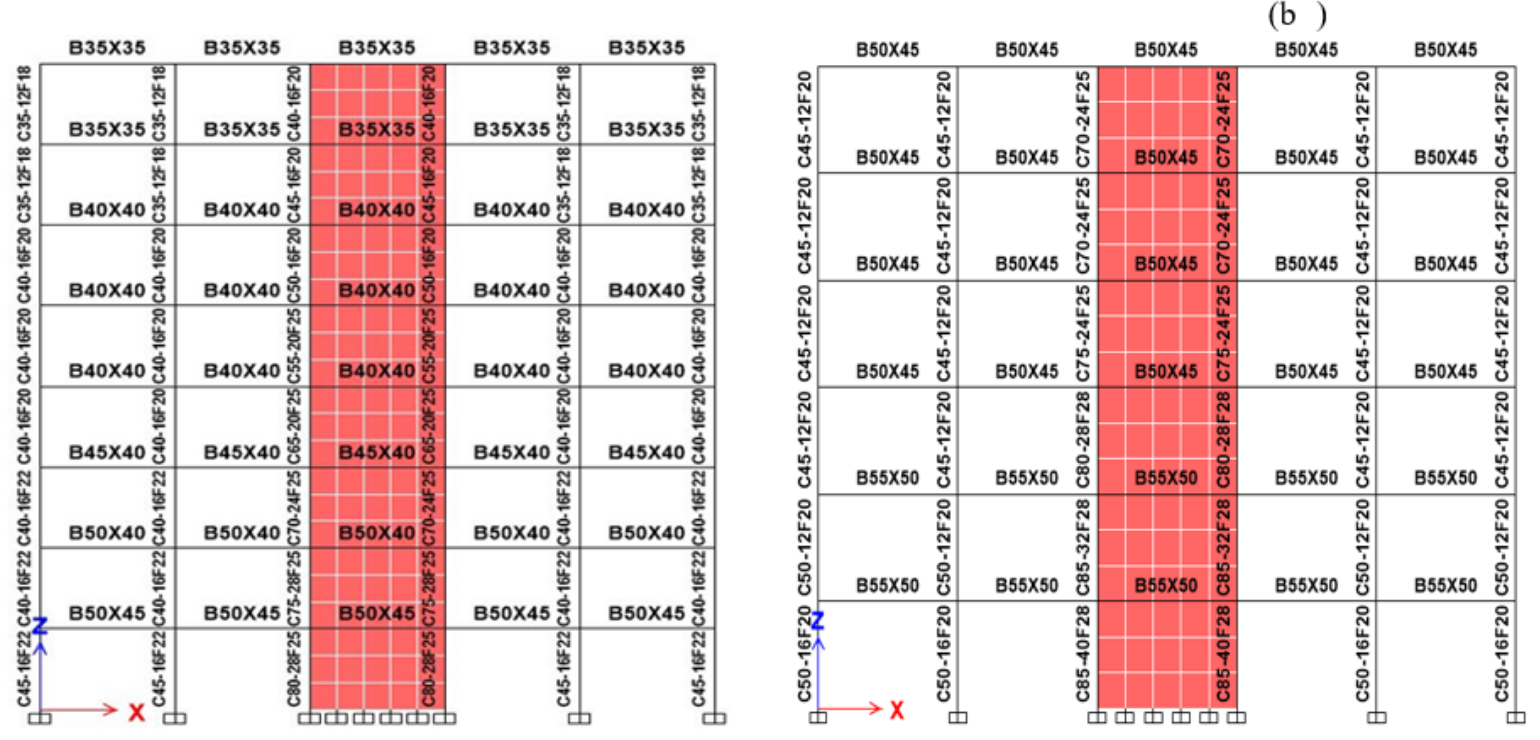

(d)

Figure 4

(a) plan of structural models (b) 4 story model (c) 8 story model (d) 6 first stories of 12 story model. 


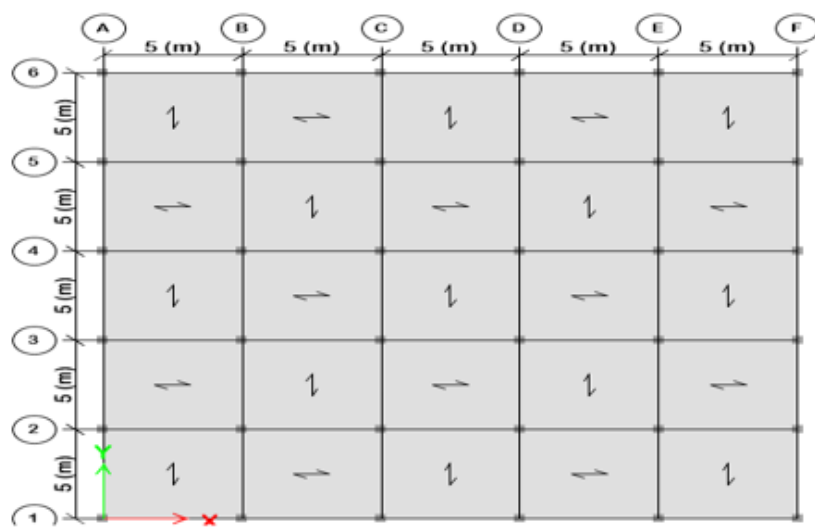

(a)

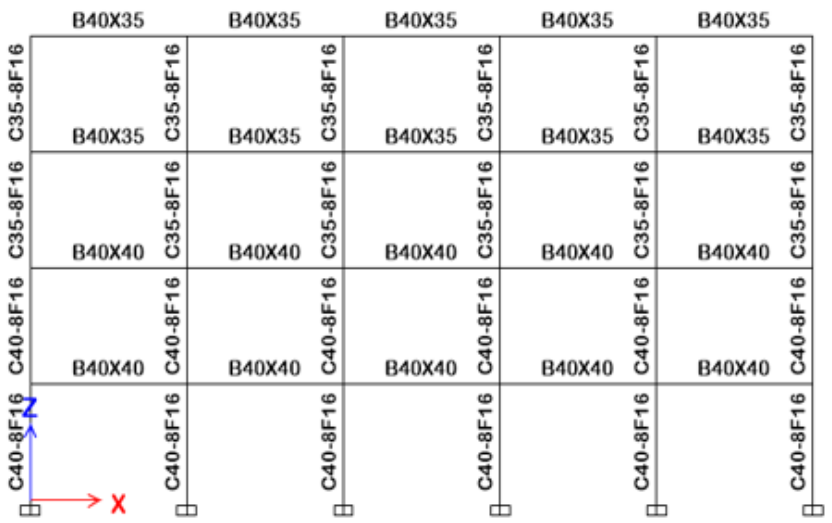

(b)

Figure 5

(a) plan of structural models (b) 4 story model of the reinforced concrete frame.

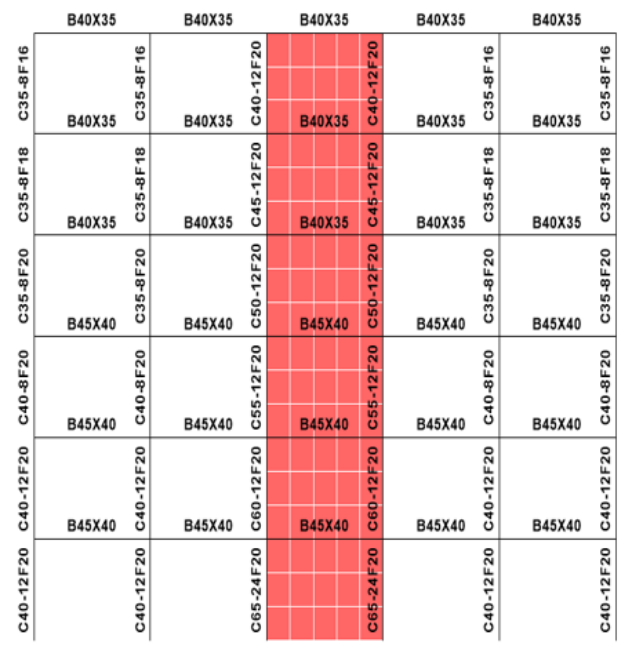

(a)

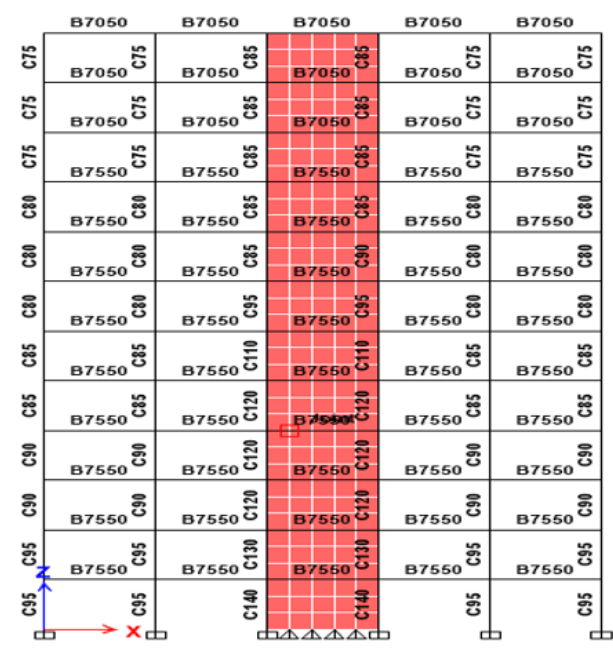

(b)

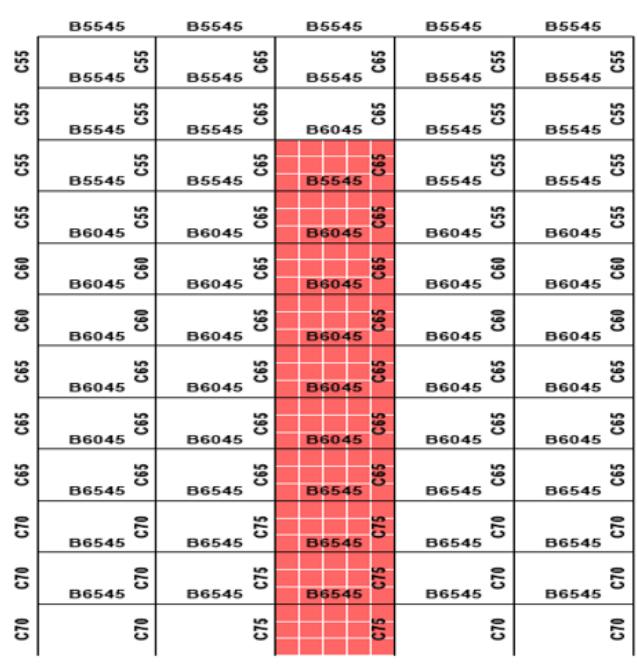

(c)

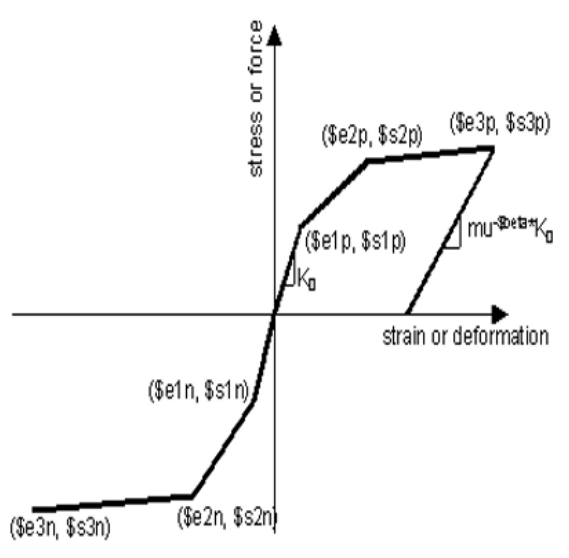

(d)

Figure 6

(a) plan of structural models (b) 4 story model of the reinforced concrete frame. 


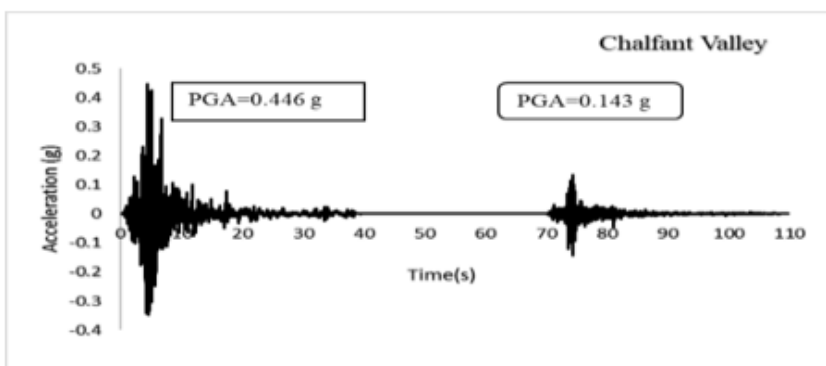

(a)

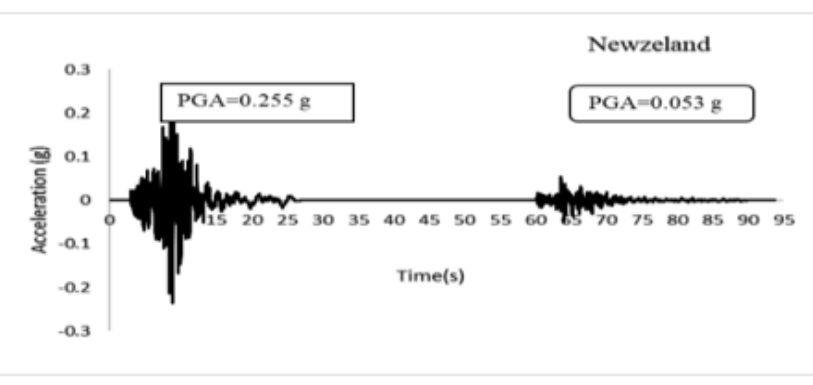

(b)

Figure 7

Seismic record sequence with effective peak acceleration a) Chalfant Valley b) New Zealand earthquakes.

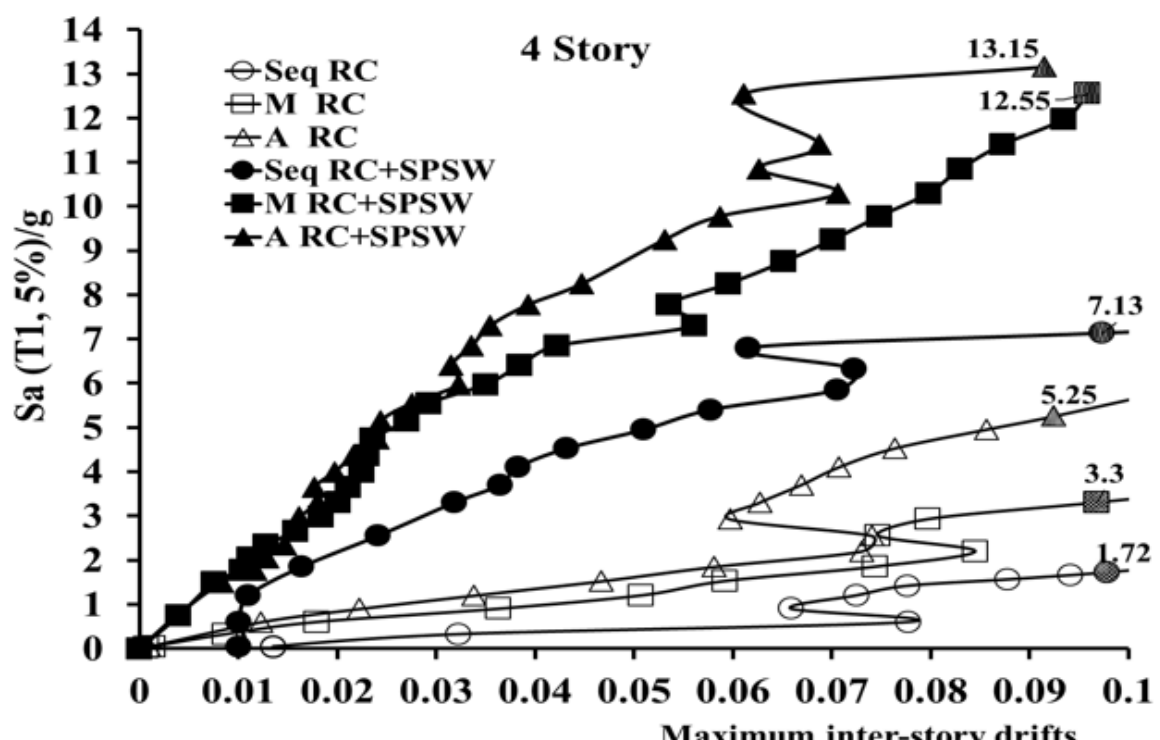

Figure 8

The compassion of 4 story model capacity with and without steel plate shear walls under the mainshock, aftershock, and sequence of seismic records Chalfant Valley of group I.

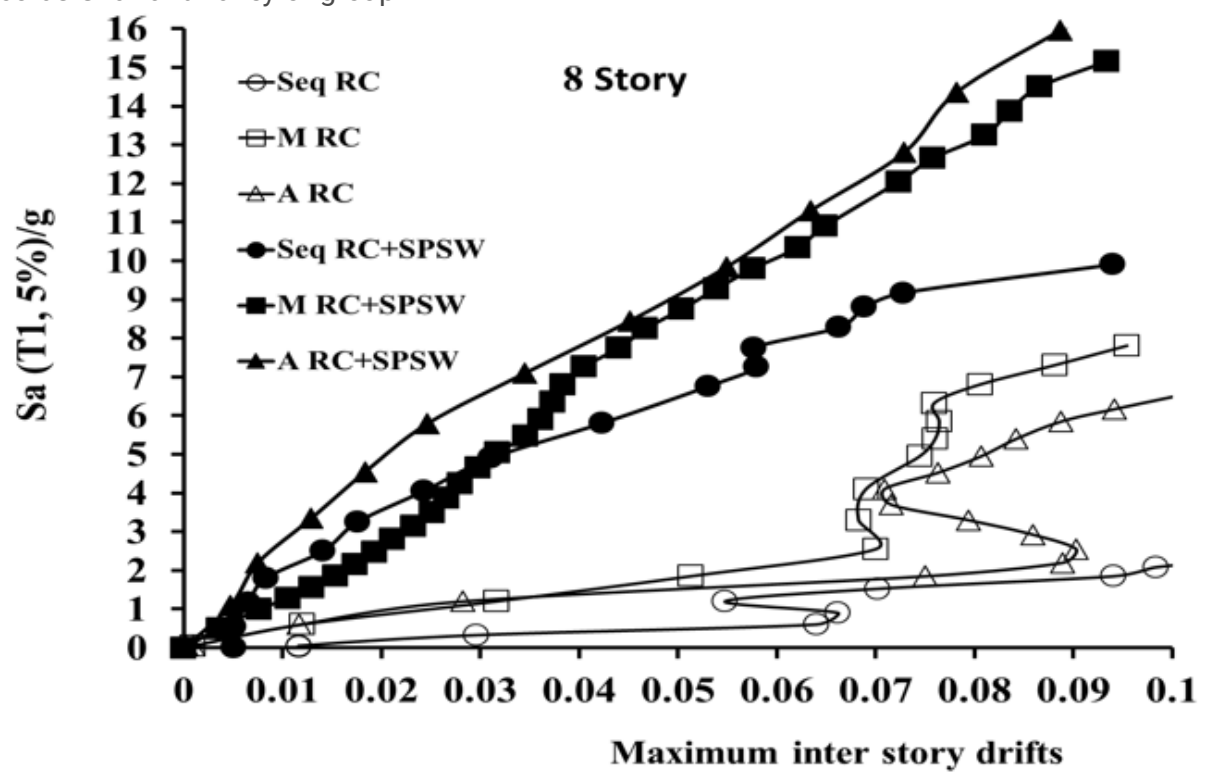

Figure 9 
The compassion of 4 story model capacity with and without steel plate shear walls under the mainshock, aftershock, and sequence of seismic records Chalfant Valley of group I.

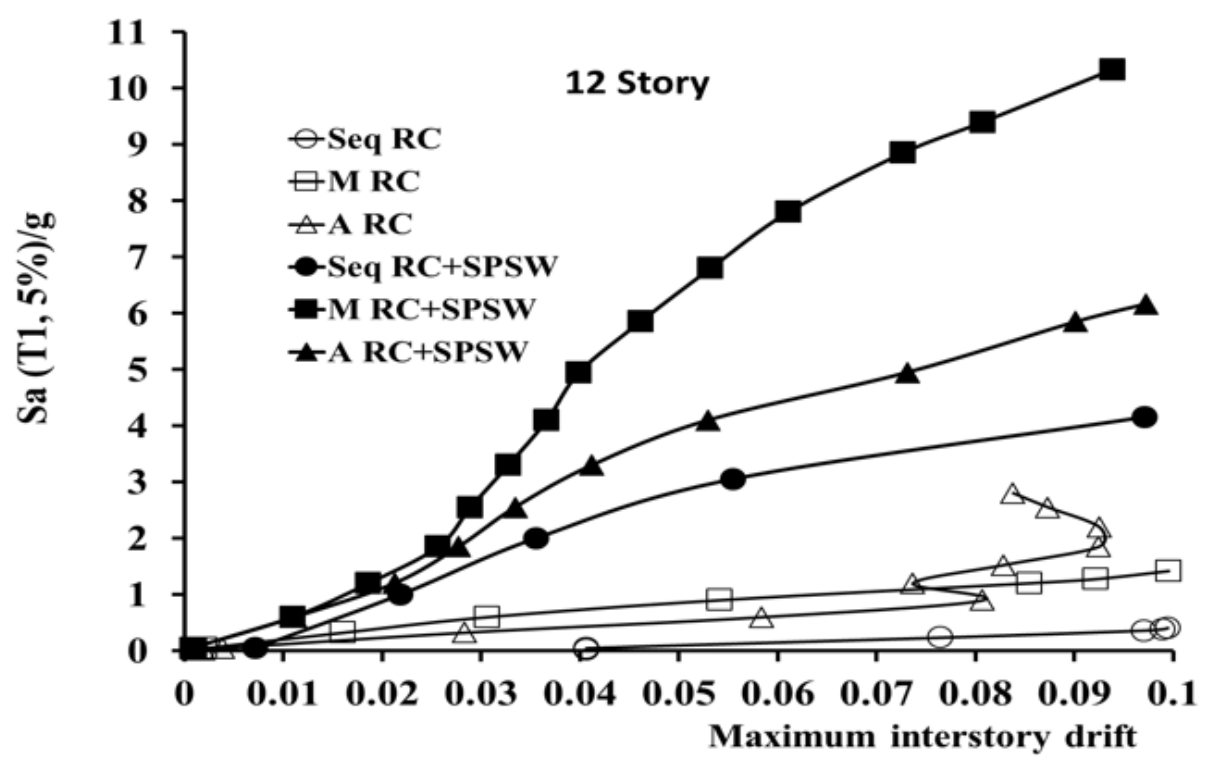

Figure 10

The compassion of 12 story model capacity with and without steel plate shear walls under the mainshock, aftershock, and sequence of seismic records Chalfant Valley of group I.

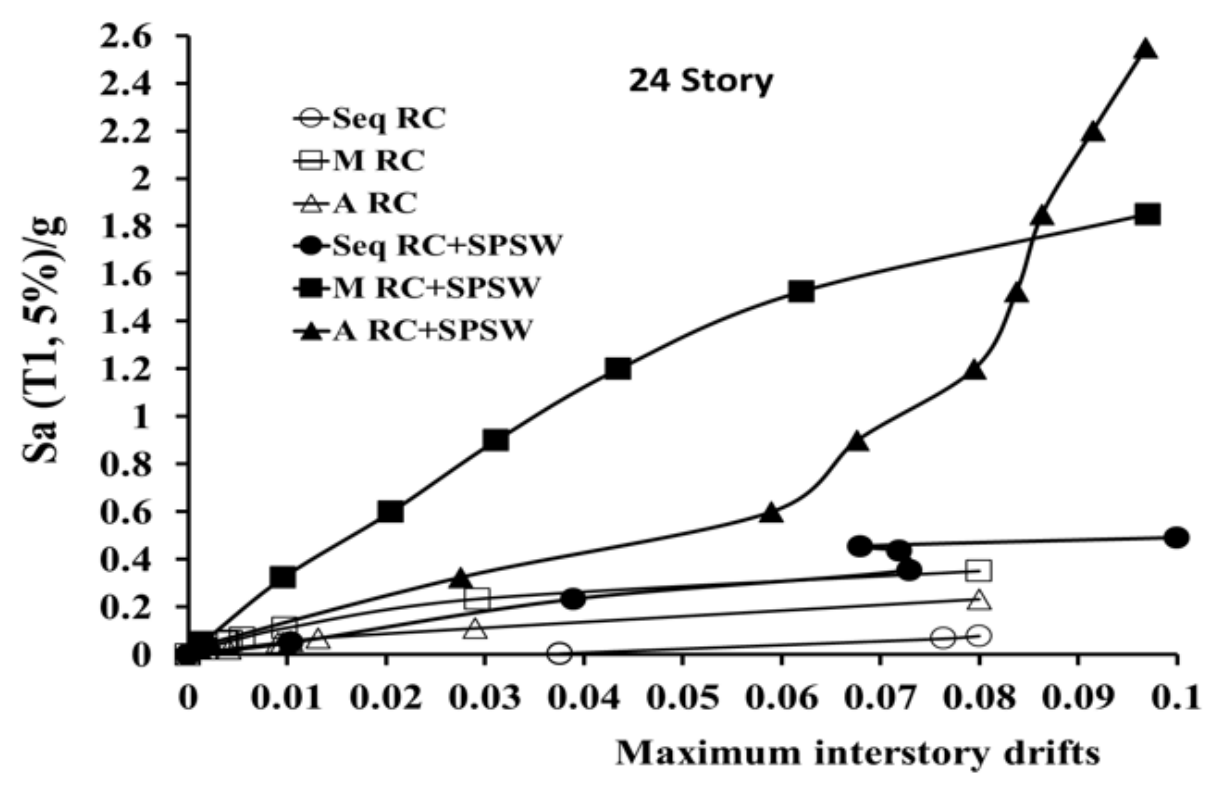

Figure 11

The compassion of 24 story model capacity with and without steel plate shear walls under the mainshock, aftershock, and sequence of seismic records Chalfant Valley of group I.

\section{Supplementary Files}

This is a list of supplementary files associated with this preprint. Click to download.

- Table5.docx 